\title{
Rule design and status quo evaluation on cross-industrial wastewater emissions trading in China's typical industrial sectors
}

Luyao Chen ${ }^{1,2}$, Hongyuan Zheng ${ }^{1,2}$ and Haizhen Yang ${ }^{1,2^{*}}$

\begin{abstract}
Background: China's industrial wastewater pollution control policy urgently needs to change from government enforcement to market economy incentive, especially in regions with mature market economic conditions and improved legislative basis like Yangtze River Delta. The economic principles of Water Emissions Trading policy are to achieve a win-win situation in which pollution could be controlled meanwhile abatement costs are minimized. Existing regulations lack rules and restrictions for cross-industrial wastewater emission trading, nevertheless not all wastewater from various industrial sectors are suitable for emissions trading with each other. This study attempted to determine tradable levels of wastewater emissions rights within the selected 10 industries based on the similarity of wastewater composition.

Results: The result is presented in a tradable level matrix. It shows that of all industrial wastewater, the most suitable for emissions trading are, respectively, Textile and Paper Production, Manufacture of General Purpose Machinery and Manufacture of Transport, and then Chemistry Production and Pharmaceuticals.

Conclusion: Generally, this paper provides a systematic calculation method according to the similarity analysis to formulate cross-industrial wastewater emissions trading for policy reference. At the end of the article, a rationality analysis of the domestic wastewater emissions trading pilot programs was made. Even though the current wastewater emissions trading situation is not up to expectations, individual enterprises actively achieved emission reductions to play as the supply sides in the wastewater emissions trading under economic incentive from such a policy.
\end{abstract}

Keywords: Industrial wastewater pollution, Emissions trading, Similarity analysis, Wastewater characteristic, Abatement cost

\section{Background}

Increasingly strict industrial pollution emission standards and the establishment of a wastewater permit system embody Chinese government attention to industrial wastewater pollution. Industrial output accounts for more than $30 \%$ of the gross domestic product (GDP) of China, with $70 \%$ of environmental pollution being of industrial origin [1]. The urgent need for improvements

\footnotetext{
*Correspondence: haizhen@tongji.edu.cn

${ }^{1}$ College of Environmental Science and Engineering, Tongji University,

No. 1239, Siping Road, Shanghai 200092, China

Full list of author information is available at the end of the article
}

in industrial water pollution management has prompted the government to take proactive action, and emission reduction schemes have been playing an effective role. Total industrial wastewater discharge has declined from 23.75 billion tonnes (Bt) in 2010 to $18.29 \mathrm{Bt}$ in 2017 [2]. However, command-and-control policies have encouraged industries to adopt passive positions with little motivation to improve [3, 4].

Emissions trading (ET) is considered an effective environmental management policy in optimizing the allocation of pollutant emissions. The concept was first proposed by Dales [5] as a means of regarding environmental resources as a property right that can be traded. 
ET encourages industries to be more proactive in controlling pollution for their own interests, with pollution control targets thus being realizable and pollution control changing from mandatory to market behavior. Such incentivizing policy promotes industrial innovation and emissions reduction more effectively than mandatory standards because the latter offers no reward for exceeding basic compliance requirements and, in theory at least, market-based ET systems are significantly more effective than traditional environmental governance policies [6-8]. Total abatement costs of such incentivizing policies, through market allocation of environmental capacity resources, are significantly lower than those of command-and-control policies in achieving the same environmental objectives [9-11]. The rapid development of the emissions trading system in international environmental law and the successful practice in Europe and America countries show that the operation of the emission trading system is feasible for the reduction of pollutants and promoting the improvement of the environment quality [12]. It provides experience and new ideas that can be used for reference in China's environmental management $[13,14]$.

Changes and development of China's environmental policies since the reform and opening up has led to a new stage marked with improved market mechanism of environmental protection [15]. As an environmental economic policy based on market rather than executive order, emission trading policy has been gradually applied in environmental management in China [16]. From policy explorations in the 1980s to domestic pilot programs since 2002, China has made beneficial attempts in establishing emission trading systems and made substantial progress. In 1990s, air pollutant emission trading started in 6 pilot cities, based on the emission permits pilot in 16 cities nationwide. The State Environmental Protection Administration (SEPA) and the United States Environmental Protection Agency (USEPA) collaborated on a program of applying market mechanism on $\mathrm{SO}_{2}$ emission reduction in China in 1999, which starts the realistic cap-and-trade policy implementation in China. In 2002, the " 4 (provinces) +3 (cities) +1 (enterprise)" program started the nationwide pilot of ET, including four provinces (Shandong, Jiangsu, Shanxi, and Henan), three cities (Shanghai, Tianjin, and Liuzhou), and one company (China Huaneng Group). ET pilot program extended to water environment field in 2007, when chemical oxygen demand (COD) and ammonia nitrogen $\left(\mathrm{NH}_{3}-\mathrm{N}\right)$ emission trading pilot program first started in Tai Lake. Soon after, it extended to river basin level, with Jiangsu, Zhejiang and Shanghai jointly participating into the pilot Wastewater Emissions Trading (WET) in Yangtze River Delta. With policies innovation and pilot programs deepening, ET platforms have been established as supporting system. Jiaxing has established China's first emission trading center to deal with WET between water pollution enterprises [12, 17, 18]. Emission trading centers have been successively established in Zhejiang, Tianjin, Shanxi, Fujian and other provinces and cities, providing enterprises guidelines and approaches to actively participate in. In addition, the emission permits in 19 industries are issued till 2019 subsequently after the first permit issued in Shanghai in 2017. With the full coverage of pollution emission permits in the industrial field in 2020, the tasks of total amount control are assigned to each enterprise, which also lays the foundation for the design of the emissions trading system [19].

From the policy perspective, WET carries the mission of environmental management policy transformation from command-control to marketization and refinement [15]. Regarding a series of environmental policies, Chinese Academy of Environmental Planning (CAEP) has given guidelines for environmental policy reforms facing 2035. It is pointed in the guidelines that with the gradual implementation of the pollution permit system, emissions trading will also move from local pilot programs to marketization, eventually forming a system. The implementation of WET requires governmental policy and regulation support, and foremost the formation of an emission right market [20]. Therefore, perfect environmental management system and excellent market economy conditions are the basis for WET development. Meanwhile, WET is better to be developed intra-regionally within river basin [21]. The Yangtze River Delta is a key area of the "Great Yangtze River Protection". From the perspective of economic and social development, the Yangtze River Delta region has a well-developed economy, complete infrastructure, and advanced development concepts. The mature market economic conditions, improved legislative basis, and appropriate government management capabilities here are a necessity and also guarantee WET development [22, 23].

However, when this environmental policy was first introduced in the economic field, it was hoped to help achieving the expected total environmental control with the minimum economic cost, thus obtaining a win-win situation for both the environment and the economy [24-26]. According to economics principles, WET occurs between two enterprises or industries whose marginal costs per unit of one pollutant are different. What our article will explain is the issues that need attention in this theoretical framework. The prerequisite of WET is that the total environmental quality does not deteriorate. Different from individual air pollutants ET such as $\mathrm{SO}_{2}$, WET deals with multiplex and non-uniform water pollutants [27]. Different emission reduction and pollution 
control costs mean that the nature of wastewater in various industries is different. The presence or absence of heavy metals, the ease of degradation of organic matter, and the level of organic matter are all factors that determine the unit cost of wastewater treatment. If WET occurs between companies belonging to the same industry, the nature of the enterprise's sewage is basically the same. It is examined who can choose cleaner production technology and improve the level of pollution control in order to gain the initiative in the WET market [28]. But in fact, WET is almost between companies in different industries. This will cause a problem-enterprises with high pollution abatement costs will easily give up pollution control and become the WET demand side. In other words, from the perspective of environmental protection, the direction of WET is not expected to be completely low-cost enterprises as suppliers, and high-cost enterprises as demanders. Rather, standard needs to be made to formulate the different industrial wastewater to trade beyond cost. The standard is to set restrictions and rules for cross-industry transactions.

Practically, it can be seen from the setting of emission trading industry coefficients in Zhejiang Province that provinces with more positive and effective WET development have begun to pay attention to cross-industry issues. However, coefficient statistics in Zhejiang Province of all industry coefficients are "1" [29]. Similarly, in Nanjing, the guidance prices of $\mathrm{COD}$ and $\mathrm{NH}_{3}-\mathrm{N}$ are different in key water pollution industries from other industries. But no fine classification is set up [30]. Obviously, WET needs such a design, but there are no rules and regulations, which requires us to study this issue and give guidelines for cross-industry transactions.

The first part of the article discusses the wastewater characteristics, treatment processes and marginal pollution control costs in typical industries. Then, a similarity principle is proposed to analyze the similarity of wastewater compositions in different industries through algorithms. At the end of the article, we evaluate the pilot WET carried out in China based on the rules formulated in this article, and point out the deficiencies and improvement methods.

\section{Methods}

\section{Data collection}

We selected 10 industries as research objects according to industrial wastewater discharge level and participation in the pilot WET. According to the Industrial Classification for National Economic Activities (ICNEA) classification, the industry types nationwide are divided into 39 categories. This article calculates the tradable level between each two of all industries. However, in view of the convenience of displaying results and discussion, this article purposefully selected 10 industries for analysis. First and foremost, industries with large amount of wastewater discharge should be included. Implementation plan of cleaner production technology in key industries of water pollution prevention was promulgated in 2016, in which 11 industries (middle categories) were confirmed as water polluting key industries [31]. To complement the industries selection, the industrial participation was calculated based on the 1668 transactions data records in representative pilot programs in Shanxi and Fujian provinces (since trading records data in other provinces or cities is lacking or not open to public) from 2012 to 2018, resulting in ten major industries. Based on the above two aspects, 10 industries are finally determined as research objects. The research on the feasibility of industrial wastewater emissions trading for these ten industries will be conducted in subsequent sections (Table 1).

Because this paper focuses on the tradability of wastewater between different industries, the nature of wastewater and the abatement cost per unit of pollutants in different industries have become the basic data. Data collection covers emissions of 12 kinds of pollutants (details in the next section), and abatement costs of ten industries, depending on publication data from China Statistical Yearbook on Environment issues 2012 to 2016, and the First National Pollution Source Investigation (NPSI; 2011). Besides, the main pollutants and treatment processes of each industry in Table 2 are summarized according to literature and Industrial Wastewater Treatment Technical Manual [32-34].

\section{Theoretical framework}

In order to establish a restriction rule on cross-industry WET, we first assess whether it is rational to determine both supply and demand enterprises simply based on pollution abatement cost. That is to say, can we only consider the interests of enterprises to motivate them to participate without policy restrictions and interventions. Table 2 shows the abatement cost, pollutants composition, and treatment methods of wastewater from different industries. By analyzing the supply and demand of WET, we explain a view that simply taking the minimization of total pollution abatement costs as the criterion for emissions trading will definitely cause pollution increase, even especially the reduction of the pollution control enthusiasm of enterprises for high abatement costs.

It can be seen from Table 2 that abatement costs of organic wastewater, inorganic wastewater and mixed wastewater are totally different. The composition and treatment methods of different types of industrial wastewater are various. In terms of environment quality of the receiving water, the nature of the wastewater from 


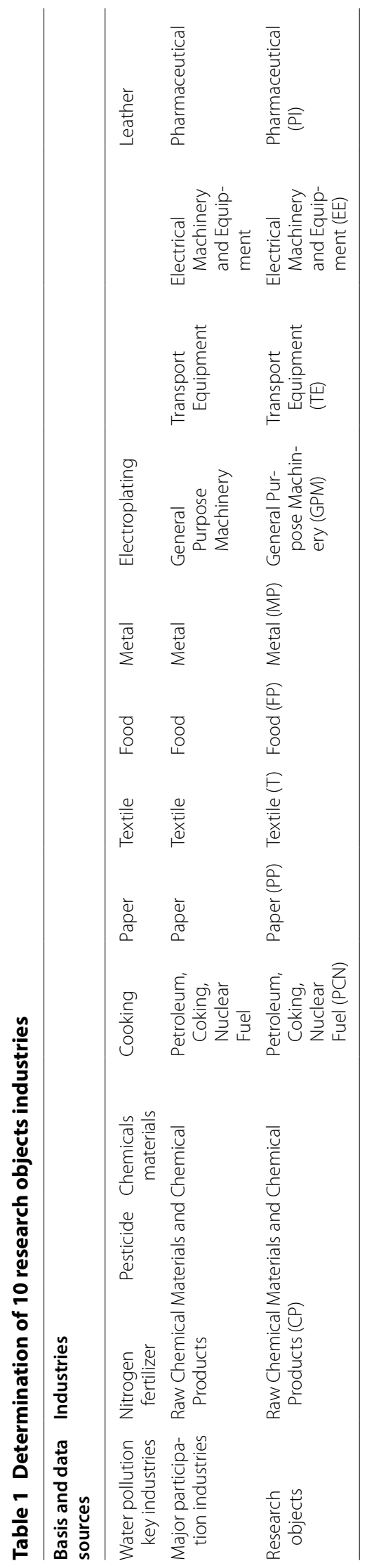


Table 2 Wastewater characteristic and treatment process and abatement cost of the ten industries as research objects

\begin{tabular}{|c|c|c|c|c|c|c|}
\hline \multirow[t]{2}{*}{ Industry } & \multirow{2}{*}{$\begin{array}{l}\text { Average } \\
\text { abatement } \\
\text { cost } y / t\end{array}$} & \multicolumn{3}{|c|}{ Contaminant characteristics } & \multirow[t]{2}{*}{ Treatment } & \multirow[t]{2}{*}{ Others } \\
\hline & & SS & Organic matter & Toxicity & & \\
\hline $\mathrm{FP}$ & 2.06 & High, food residue & $\begin{array}{l}\text { High, easily degra- } \\
\text { dable }\end{array}$ & Low & Biological & - \\
\hline $\mathrm{T}$ & 2.28 & Cotton, wool and fiber & $\begin{array}{l}\text { High, } 10-80 \% \text { degra- } \\
\text { dable }\end{array}$ & Surfactant and dye & $\begin{array}{l}\text { Physicochemical, } \\
\text { biological, advanced } \\
\text { oxidation }\end{array}$ & $\begin{array}{l}\text { High temperature and } \\
\text { chroma }\end{array}$ \\
\hline $\mathrm{PP}$ & 1.93 & Mud and fiber & $\begin{array}{l}\text { High, } 10-50 \% \text { degra- } \\
\text { dable }\end{array}$ & $\begin{array}{l}\text { Resin acid, unsatu- } \\
\text { rated fatty acid }\end{array}$ & $\begin{array}{l}\text { Physicochemical, } \\
\text { biological, advanced } \\
\text { oxidation }\end{array}$ & - \\
\hline PCN & 5.6 & Silt and clay & $\begin{array}{l}\text { High, hardly bio- } \\
\text { degradable, high } \\
\text { petroleum }\end{array}$ & Heavy metals & $\begin{array}{l}\text { Physicochemical, } \\
\text { biological, chemi- } \\
\text { cal flocculation, } \\
\text { advanced oxidation }\end{array}$ & $\begin{array}{l}\text { High temperature and } \\
\text { strong acidity or } \\
\text { basicity }\end{array}$ \\
\hline $\mathrm{CP}$ & 3.64 & - & $\begin{array}{l}\text { High, hardly biode- } \\
\text { gradable }\end{array}$ & $\begin{array}{l}\text { High, heavy metals, } \\
\text { cyanide, phenol }\end{array}$ & $\begin{array}{l}\text { Physicochemical, } \\
\text { biological, electro- } \\
\text { chemical }\end{array}$ & High temperature \\
\hline $\mathrm{Pl}$ & 4.07 & $\begin{array}{l}\text { High, microbial thallus, } \\
\text { gruff }\end{array}$ & $\begin{array}{l}\text { High, hardly biode- } \\
\text { gradable }\end{array}$ & Antibiotics & $\begin{array}{c}\text { Physicochemical, bio- } \\
\text { logical, flocculation }\end{array}$ & - \\
\hline MP & 6.85 & High, inorganic & Low & Heavy metal & $\begin{array}{l}\text { Physicochemical, floc- } \\
\text { culation, sedimenta- } \\
\text { tion }\end{array}$ & - \\
\hline GPM & 6.2 & - & $\begin{array}{l}\text { High, hardly biode- } \\
\text { gradable }\end{array}$ & Heavy metal, cyanide & $\begin{array}{l}\text { physical, chemical, } \\
\text { advanced oxidation }\end{array}$ & - \\
\hline $\mathrm{TE}$ & 4.27 & - & $\begin{array}{l}\text { High, hardly biode- } \\
\text { gradable, engine oil }\end{array}$ & Heavy metal & $\begin{array}{l}\text { Flocculation and } \\
\text { sedimentation, } \\
\text { advanced oxidation }\end{array}$ & - \\
\hline $\mathrm{EE}$ & 4.37 & - & $\begin{array}{l}\text { High, hardly biode- } \\
\text { gradable }\end{array}$ & Heavy metal, cyanide & $\begin{array}{l}\text { Flocculation and } \\
\text { sedimentation, } \\
\text { advanced oxidation }\end{array}$ & - \\
\hline
\end{tabular}

the supply side and the demand side should not differ a lot. WET should be better not developed between any two enterprises or industries which are quite different in wastewater composition, and then treatment process, technical difficulty and abatement costs. Assume that company $\mathbf{A}$ in the food industry sold 1 ton COD of emission rights to $\mathbf{B}$ in the pharmaceutical industry. Under this circumstance, for the entire water environment, the $1 \mathrm{t}$ wastewater from the food industry was not discharged into the water body, and was replaced by $1 \mathrm{t}$ pharmaceutical wastewater. The composition and degradability of COD in the food industry is not consistent with that of the pharmaceutical industry. What's more, the same amount of wastewater in the pharmaceutical industry contains more toxic substances, such as heavy metals. Arbitrary trading will increase the burden on the water environment. Based on the above theoretical analysis, the "similarity principle" is proposed.

The theoretical assumption is that the more similar any two industrial wastewater characteristic is, the less the additional pollution is, thus the more tradable these two industrial wastewater is. To compare the similarity between each two of various industrial wastewater, evaluation indicators are of vital importance $[35,36]$. This article judges the similarity of the components of wastewater in different industries to determine whether the industries to which the two parties belong are suitable to participate in WET. The calculation of the similarity of the wastewater composition is carried out by simplifying a certain type of wastewater into a vector with several specific indicators. Generally, conventional monitoring

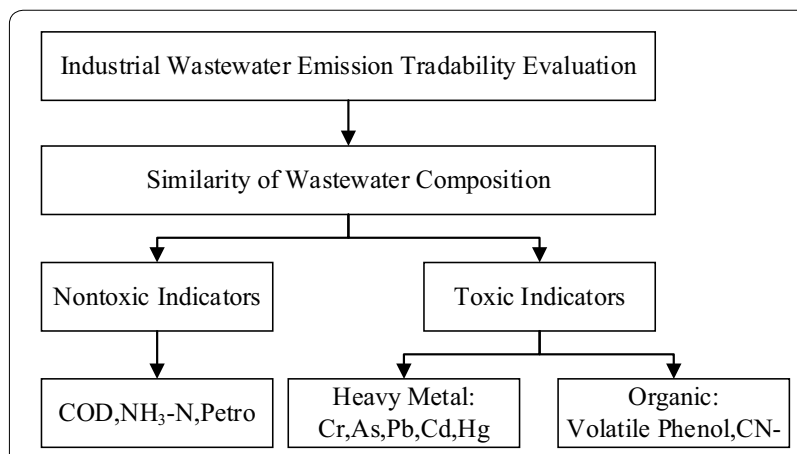

Fig. 1 Determination of conventional monitoring pollutant as evaluation indicators 
indicators in industrial wastewater are classified into the categories shown in Fig. 1. A selection of 12 indicators are based on representative and data availability. These 12 indicators cover general organics, toxic organics and heavy metals. The indicators we selected are the pollutant indicators used in environmental investigation and statistics to guarantee the correct source of the calculated data. For the absence of data of BOD, in order to distinguish the biodegradability of different COD, COD easy, $\mathrm{COD}_{\text {able }}, \mathrm{COD}_{\text {difficult }}$, respectively, represent easily, ably, difficultly degradable parts of COD. Usually, wastewater with biodegradability exceeding $45 \%$ is determined as easily degradable wastewater; if below $20 \%$, then difficultly degradable wastewater; others able to degradable. Referring to Industrial Wastewater Treatment Technical Manual [32-34], we define the wastewater COD in the targeted industries. In order to simplify the calculation, taking food industry as an example, if COD of the wastewater is determined as easily degradable, then the value of $\mathrm{COD}_{\text {easy }}, \mathrm{COD}_{\text {able }}, \mathrm{COD}_{\text {difficult }}$ are, respectively, equal to value of $\mathrm{COD}, 0,0$. In the analysis section, calculation and evaluation of similarity will be developed based on the emission data from each industry of these 12 indicators: $\mathrm{COD}_{\text {easy }}, \mathrm{COD}_{\text {able }}, \mathrm{COD}_{\text {difficult }}, \mathrm{NH}_{3}-\mathrm{N}$, Petro, Volatile Phenol (VP), Cyanide (CN-), Cr, As, Pb, Cd, Hg.

\section{Method and analysis \\ Similarity evaluation of industrial wastewater}

First we make an assumption on original data processing. Wastewater from the different enterprises belonging to the same industry type involved in WET are not exactly the same. Therefore, to simplify the analysis to compare wastewater similarities across industries, an industrial average emission value was set up to represent wastewater emissions in one industry type, based on data from the NPSI (2011). Thus, the total 39 wastewater characterized by 12 typical pollutants represent the 39 industrial wastewater nature, as the basic analysis data in the following discussion. (We calculated the data of 39 industries in Industrial Classification for National Economic Activities (ICNEA), but when analyzing, we only targeted at 10 typical industries selected.)

The concentration of pollutants $i(i \in(1, \ldots, 12))$ in industry $j(j \in(1, \ldots, 39))$ is $P_{i j}(\mathrm{mg} / \mathrm{L})$, from which matrix $(P)_{12 \times 39}$ could be derived. $(12 \times 39)$ represents the matrix dimension, with the rows representing the types of pollutant and the columns the types of industry. A problem is that due to the large difference in the concentration of various pollutants in wastewater (for example, the concentration of COD in almost all industries will be much greater than the concentration of chromium), different effects in the composition similarity evaluation will be caused. Therefore, in order to eliminate magnitude differences of various pollutants, we normalize the pollutants $i(i \in(1, \ldots, 12))$ in wastewater from 39 industries, Eq. (1) as follows:

$$
P_{u, i j}=\frac{P_{i j}-\min \left(P_{i}\right)}{\left(\max \left(P_{i}\right)-\min \left(P_{i}\right)\right)},
$$

where $P_{u, i j}$ represents the concentration of pollutants after normalization, $P_{u, i j} \in[0,1], P_{u, i j}$ is dimensionless; $P_{i}$ represents the row $i$ of the matrix $(P)_{12 \times 39}$.

The normalized concentration value is used to calculate the similarity of wastewater composition between any two industries. There are many methods for analyzing the similarity of two sets of data in mathematics, such as Pearson correlation coefficient, Euclidean distance, cosine similarity, Jensen-Shannon divergence, and so on. Among the above, the cosine similarity is specifically used to analyze the similarity of compositions, and the calculation method is simple. Thus this article uses the Cosine Similarity [37] method to analyze the similarity of pollutant compositions in wastewater from various industries. We assume that the similarity between industry $m$ and industry $n$ is $S_{m n}$, and its calculation is shown below as Eq. (2):

$$
S_{m n}=\frac{\sum_{i=1}^{12}\left(P_{u, i m} P_{u, i n}\right)}{\sqrt{\sum_{i=1}^{12} P_{u, i m}^{2}} \sqrt{\sum_{i=1}^{12} P_{u, i n}^{2}}}
$$

where $m, n \in(1, \ldots, 39), S_{m n} \in[0,1]$, and the closer $S_{m n}$ is to 1 , the higher the similarity; and the closer it is to 0 , the lower the similarity.

\section{Entropy-weighting method}

In the above similarity analysis, the weights of 12 indicators are the same. However, wastewater characteristic should not be evaluated only by the concentration of each pollutant, but the respective weighting value of 11 pollutants. As mentioned earlier, non-toxic pollutants (e.g., $\mathrm{COD}, \mathrm{NH}_{3}-\mathrm{N}$ ) are the main composition of wastewater. The concentration of non-toxic pollutants directly determines the nature of the wastewater such as whether the wastewater is organic or inorganic wastewater. Meanwhile, the content of toxic pollutants is relatively low, but it directly determines the toxicity of wastewater. Therefore, in this article, in order to distinguish the role of various pollutant compositions in the similarity evaluation of wastewater, different weights are given to 12 pollutants. For example, the 
weight of the pollutant $i$ is $\omega_{i}$, Eq. (2) can be further deduced as Eq. (3):

$$
S_{\omega, m n}=\frac{\sum_{i=1}^{12}\left(\omega_{i}^{2} P_{u, i m} P_{u, i n}\right)}{\sqrt{\sum_{i=1}^{12} \omega_{i}^{2} P_{u, i m}^{2}} \sqrt{\sum_{i=1}^{12} \omega_{i}^{2} P_{u, i n}^{2}}},
$$

where $S_{\omega, m n}$ is the similarity considering the weight of various pollutants.

Then, we can get the similarity coefficient matrix $\left(S_{\omega}\right)_{39 \times 39}$ between all industries considering the weight of each pollutant, where $39 \times 39$ represents the matrix dimension, and it is a symmetric matrix.

The point now is how to determine the weights of 12 pollutants. As discussed earlier, in terms of the nature of industrial wastewater, with the principle of no pollutants addition, industries with organic wastewater and with inorganic wastewater are not suggested to participate in as supply and demand sides in WET. Similarly, toxic wastewater and non-toxic wastewater are not considered to be tradeable. The total weights of the two categories of indicators, toxic and non-toxic, is determined the same. This is also the difference between similarity evaluation and water quality evaluation. Water quality evaluation focuses on toxicity equivalents, while similarity evaluation pays more attention to the differences between the 12-dimensional vectors. At the toxicity levels, equal weight is given to both types of indicators. As to weight of the respective compositions in the non-toxic and the toxic part, we use the entropy weight method to allocate [38-40].

The entropy-weighting method is used to evaluate the effect of indicators on the evaluation from aspect of disorder degree; the greater the discrepancy of the value among the evaluation on the same indicators is, the greater the impact of the indicator on the overall evaluation. Comparing with traditional methods such as Analytic Hierarchy Process, the entropy-weighting is relatively objective in weight determination since the weighting only determined by the data dispersion itself. The entropy weight method can effectively amplify the difference in composition similarity evaluation by increasing the weight. For example, if the concentration of the pollutant $i$ is relatively close in 39 industries, then it proves that the pollutant has a smaller role in the composition similarity evaluation, so a smaller weight is assigned for the pollutant $i$, and vice versa. The calculation steps of the entropy weight method are shown below:

1. Calculating the entropy of 12 pollutants, the formula is as follows:

$$
E_{i}=-\frac{1}{\ln 39} \sum_{j=1}^{39} P_{u, i j} \ln P_{u, i j},
$$

where $i \in(1, \ldots, 12), j \in(1, \ldots, 39)$.

2. Calculating the entropy-weighting of 12 pollutants, the formula is as follows:

$$
\omega_{i}=\frac{1-E_{i}}{m-\sum_{i=1}^{m} E_{i}} .
$$

According to the above method, entropy weights of 12 pollutants are shown in Table 3.

\section{Fuzzy-logic classification of industrial wastewater tradability}

The fuzzy-logic evaluation method $[41,42]$ was used to classify tradable levels of emissions based on the similarity coefficient obtained using Eq. (3) where the matrix $\left(S_{e}\right)_{n \times n}$ is a Symmetric Matrix. Therefore, as to the similarity classification, only the lower triangular part of the matrix (the diagonal and its lower parts) needs to be considered. By arranging elements in the $\left(S_{e}\right)_{n \times n}$ matrix into a vector $V_{e}$ from small to large, and obtaining the quartiles of the vector $\left(Q_{1}, Q_{2}\right.$, and $\left.Q_{3}\right)$, the tradable level of pollutants can be divided into five levels, $\mathrm{I}-\mathrm{V}$ (where $\mathrm{V}$ is the most suitable trading level and I the most $L_{m n}$ unsuitable). The triangular membership function (Fig. 2) is selected to calculate membership of each level.

Table 3 Entropy weighting of 12 indicators in similarity evaluation

\begin{tabular}{lllllll}
\hline Indicator & $\mathrm{COD}_{\mathbf{e}}$ & $\mathrm{COD}_{\mathbf{a}}$ & $\mathbf{C O D}_{\mathbf{d}}$ & Petro & $\mathbf{N H}_{\mathbf{3}}-\mathbf{N}$ & $\mathbf{V P}$ \\
\hline$\omega_{i}$ & 0.187 & 0.13 & 0.043 & 0.073 & 0.067 & 0.075 \\
\hline Indicator & $\mathbf{C N}-$ & $\mathbf{C r}$ & $\mathrm{As}$ & $\mathbf{P b}$ & $\mathbf{C d}$ & $\mathbf{H g}$ \\
\hline$\omega_{i}$ & 0.071 & 0.08 & 0.072 & 0.064 & 0.091 & 0.047 \\
\hline
\end{tabular}




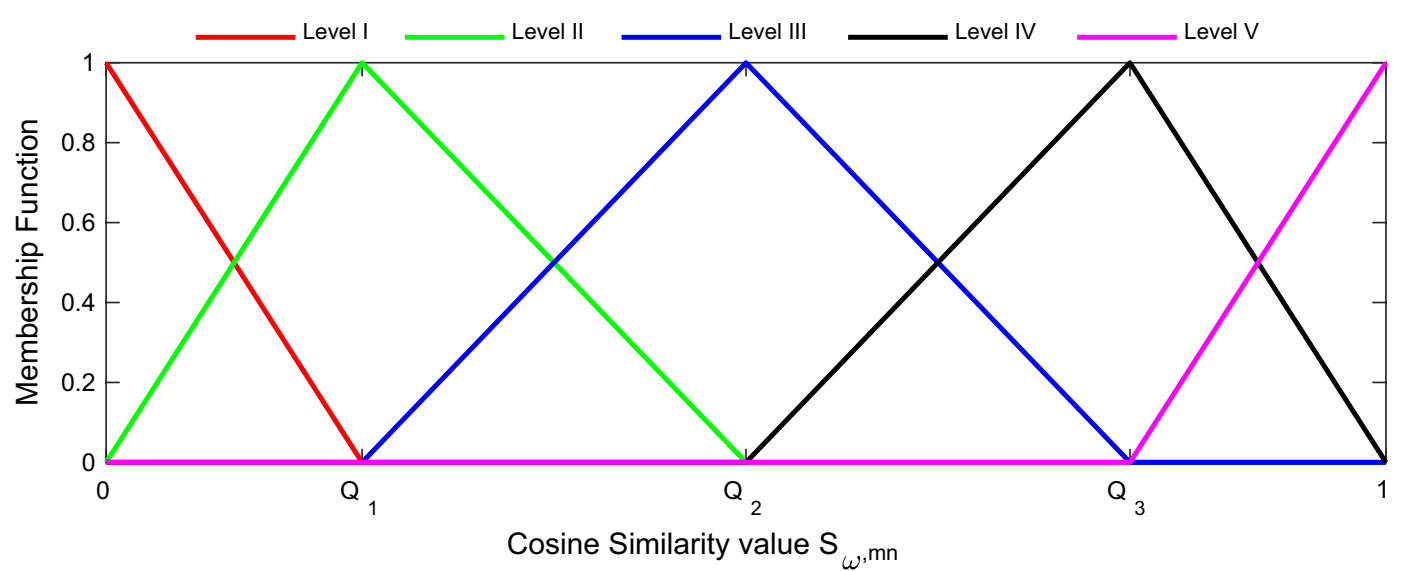

Fig. 2 Membership function of different tradable levels

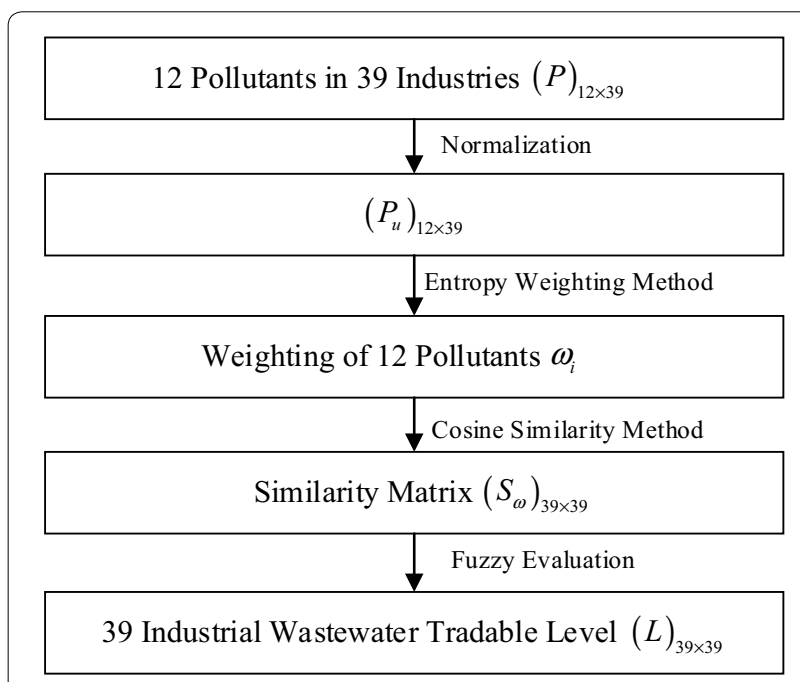

Fig. 3 Flowchart of the whole algorithm

The five membership values of the element $S_{\omega, m n}$ in matrix $\left(S_{\omega}\right)_{39 \times 39}$ are $M_{m n}^{\mathrm{I}}, M_{m n}^{\mathrm{II}}, M_{m n}^{\mathrm{III}}, M_{m n}^{\mathrm{IV}}$, $M_{m n}^{\mathrm{V}}$. Tradability levels of industries $m$ and $n$ are determined by the maximum of these five values $\left(\max \left(M_{m n}^{\mathrm{I}}, M_{m n}^{\mathrm{II}}, M_{m n}^{\mathrm{III}}, M_{m n}^{\mathrm{IV}}, M_{m n}^{\mathrm{V}}\right)\right)$.

The flowchart of the whole algorithm is shown in Fig. 3.

\section{Results and discussion}

The similarity evaluation finally gives a tradable level classification matrix as shown in Fig. 4. This is a symmetric matrix. We only consider the tradable level of industrial wastewater with each other, but do not specify which is supply. In order to explain the results of the matrix in detail, we selected the 6 groups that are most suitable for trading (level V and IV) as shown in Table 4.

\begin{tabular}{|c|c|c|c|c|c|c|c|c|c|}
\hline & FP & $\mathrm{T}$ & PP & PCN & $\mathrm{CP}$ & PI & MP GPI & $1 \mathrm{TE}$ & EE \\
\hline FP & {$[\mathrm{V}$} & II & II & II & II & II & II & II & II 7 \\
\hline $\mathrm{T}$ & II & $\mathrm{V}$ & $\mathrm{V}$ & II & II & II & II II & III & III \\
\hline PP & II & $\mathrm{V}$ & $\mathrm{V}$ & II & II & II & II II & III & III \\
\hline $\mathrm{PCN}$ & II & II & II & V & IV & III & II II & II & III \\
\hline $\mathrm{CP}$ & II & II & II & IV & V & IV & II & II & III \\
\hline PI & II & II & II & III & IV & $\mathrm{V}$ & II & II & II \\
\hline MP & I & II & II & II & II & II & $\mathrm{V} \quad$ III & III & II \\
\hline GPM & II & II & II & II & II & II & III $\mathrm{V}$ & V & IV \\
\hline $\mathrm{TE}$ & II & III & III & II & II & II & III $\mathrm{V}$ & $\mathrm{V}$ & IV \\
\hline $\mathrm{EE}$ & II & III & III & III & III & II & II IV & IV & $\mathrm{V}$ \\
\hline
\end{tabular}

Fig. 4 Tradable level matrix of ten typical industries $(L)_{10 \times 10}$

Table $4 \mathrm{~V}$ and IV tradable level industrial matching

\begin{tabular}{llllll}
\hline Industries & $\boldsymbol{L}_{\boldsymbol{m} \boldsymbol{n}}$ & $\boldsymbol{S}_{\boldsymbol{\omega}, \boldsymbol{m} \boldsymbol{n}}$ & Industries & $\boldsymbol{L}_{\boldsymbol{m} \boldsymbol{n}}$ & $\boldsymbol{S}_{\boldsymbol{\omega}, \boldsymbol{m} \boldsymbol{n}}$ \\
\hline T-PP & $\mathrm{V}$ & 0.993 & TE-EE & IV & 0.515 \\
GPM-TE & $\mathrm{V}$ & 0.986 & PCN-CP & IV & 0.4791 \\
CP-PI & IV & 0.7748 & GPM-EE & IV & 0.4775 \\
\hline
\end{tabular}

As can be seen from the results, the 3 pairs of industries that are most suitable for trading are, respectively, Textile and Paper Production, Manufacture of General Purpose Machinery and Manufacture of Transport, and then Chemistry Production and Pharmaceuticals. The similarity of the 3 pairs of industrial categories on the right side of the table is relatively low, and the wastewater of these industries is partially tradable. Consistent with the previous analysis section, the nature and treatment 
of each pair of these two industrial wastewaters are similar. In other words, industrial wastewater that are permitted to trade with each other can be classified into categories: non-degradable organic wastewater (e.g., Textile and Paper Production), wastewater with chemicals (e.g., Chemistry Production and Pharmaceuticals), and machinery manufacturing wastewater (e.g., Manufacture of General Purpose Machinery and Manufacture of Transport). Industries outside this category are not allowed to trade. For example, within the ten industries in this paper, the wastewater from food products is of high biodegradability without toxic matter, thus could not be traded with others. It should be noted that in practice, before each transaction is approved, it should be strictly reviewed by the government management department.

To determine whether tradable levels classification is reasonable and effective mathematically, we defined the average of the pollutant difference values $\delta$ of both supply and demand parties, from 12 indicators, respectively, belonging to a certain transaction level (e.g., Class V), as described by Eq. (6):

$$
\delta_{i}^{\mathrm{V}}=\frac{\sum_{(m, n) \in \mathrm{V}}\left|P_{u, i m}-P_{u, i n}\right|}{n_{1}},
$$

where $i$ represents a pollutant, $\mathrm{V}$ is the tradable level, $(m, n) \in \mathrm{V}$ indicates that WET between industries $m$ and $n$ is of level $\mathrm{V}$, and $n_{1}$ represents the number of level $\mathrm{V}$ in the classification matrix.

Average difference values for pollutants of different levels are shown in Table 5. As the tradable level increases, the difference value decreases, indicating that the classification of tradable levels is in line with the hypothesis of similarity: the higher the tradable level, the closer the composition of contaminants, and the smaller the additional water pollution.

\section{Case study}

So far, 28 pilot provinces or cities in China successively carried out ET program. As of August 2018, the accumulated charges for the use of pollution rights in the primary market amounted to 11.77 billion yuan, among which the amount in the secondary market was 7.23 billion yuan [43]. Zhejiang is far ahead with a total transaction value of more than 6 billion yuan, followed by Shanxi and Fujian with over 1 billion transaction value. However, the effectiveness and rationality of the WET carried out remains to be tested. Reviews of WET programs in recent years will give positive feedback for improvement.

Based on the trading rules that have been derived from the above, we analyze the pilot WET programs that have been carried out in China, with assessment and suggestions for improvement provided. Because of the lack of open data in Zhejiang, Jiangsu and other provinces and cities in the Yangtze River Delta, we selected Fujian in the eastern coastal regions and Shanxi province in the central region as the analysis objects. Economic levels, industrial structures, and levels of pollutant emissions vary, causing pilot work in these areas representative. We hope that it can share experiences for the future development of WET in the Yangtze River Delta. Transaction record data for analysis are originally from local WET Center.

The general WET development situations are concluded in Fig. 5a, b. It can be seen that the proportion of trading between enterprises in Fujian Province is large, while Shanxi Province is quite the opposite, most of WET from government to enterprises. This is related to the establishment of supporting legal systems and the degree of economy marketization. Obviously, WET in Fujian Province is more in line with the original intention of the environmental economic system, with more initiative given to market from government. In order to better reflect the transaction situation, the concepts of transaction volume $(\mathrm{V})$ and participation rate $(\mathrm{P})$ of each industry are proposed. The transaction volume refers to the ratio of the transaction volume between certain two industries to the total transaction volume; and the participation rate refers to the ratio of the number of transactions between the two industries to the total number of transactions. Under the premise of this definition, if the participation is high and the transaction volume is low, it means that small and medium-sized enterprises are more involved; if the participation is low and the transaction

Table 5 Average difference values from pollutants transaction at different trading levels

\begin{tabular}{lcccccccccccc}
\hline $\begin{array}{l}\text { Unit } \\
\mathbf{x} \mathbf{1 0}^{-\mathbf{2}}\end{array}$ & $\mathbf{C O D}_{\mathbf{e}}$ & $\mathbf{C O D}_{\mathbf{a}}$ & $\mathbf{C O D}_{\mathbf{d}}$ & Petro & $\mathbf{N H}_{\mathbf{3}}-\mathbf{N}$ & $\mathbf{V P}$ & $\mathbf{C N}-$ & $\mathbf{C r}$ & $\mathbf{A s}$ & $\mathbf{P b}$ & $\mathbf{C d}$ & $\mathbf{H g}$ \\
\hline$\delta_{i}^{!}$ & 56.8 & 11.6 & 10.2 & 13.3 & 10.8 & 12.3 & 20.1 & 20.1 & 6.46 & 5.22 & 1.07 & 19.7 \\
$\delta_{i}^{\| !}$ & 25.1 & 14.5 & 19.3 & 13.9 & 16.2 & 8.46 & 8.67 & 10.1 & 11.1 & 10.6 & 7.62 & 16.4 \\
$\delta_{i}^{\| !}$ & 0 & 3.53 & 18.3 & 18.8 & 26.7 & 19.1 & 10.8 & 17.8 & 9.81 & 9.94 & 7.4 & 18.3 \\
$\delta_{i}^{\mid V}$ & 0 & 1.99 & 13.3 & 11.6 & 7.92 & 3.43 & 2.01 & 1.59 & 6.02 & 7.05 & 3.83 & 11.2 \\
$\delta_{i}^{V}$ & 0 & 0.43 & 13.5 & 6.96 & 3.72 & 0.99 & 0.7 & 0.43 & 1 & 1.37 & 0.46 & 2.06 \\
\hline
\end{tabular}




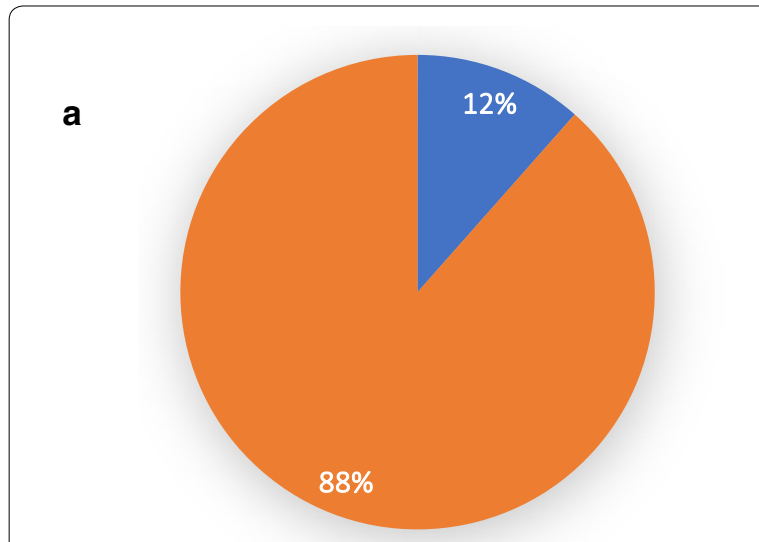

- Government to enterprises COD transaction volume/t - Enterprise to enterprise transaction volume/t

\section{b}

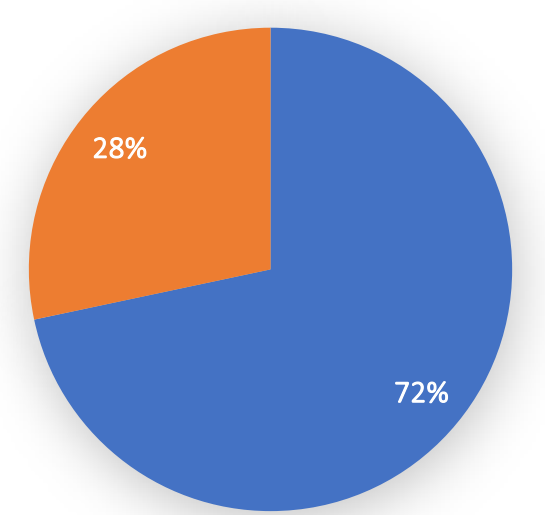

- Government to enterprises COD transaction volume/t - Enterprise to enterprise transaction volume/t

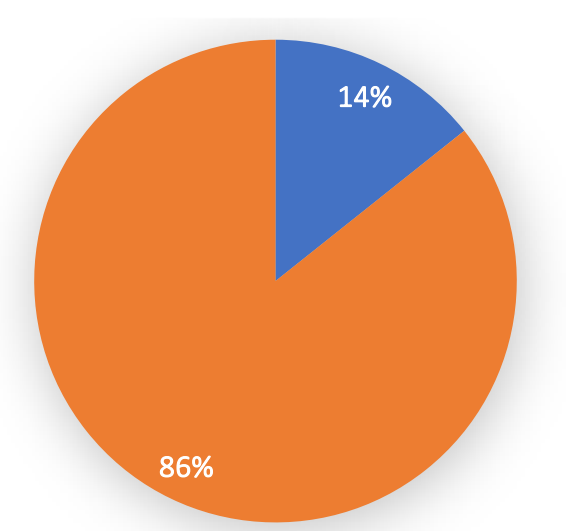

- Government to enterprises NH3-N transaction volume/t - Enterprise to enterprise transaction volume/t

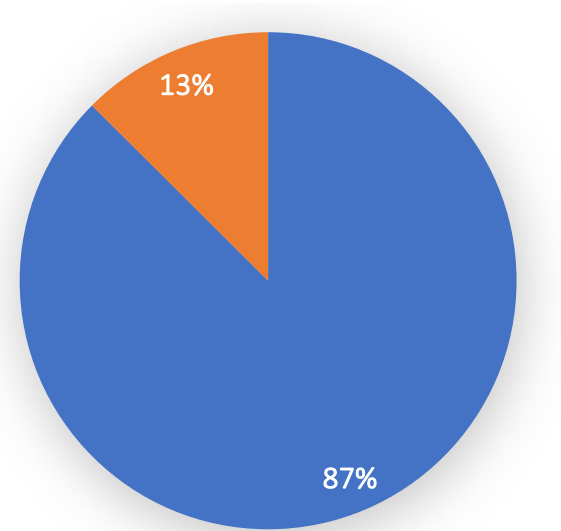

- Government to enterprises NH3-N transaction volume/t Enterprise to enterprise transaction volume/t

Fig. 5 Proportion of trading between enterprises in Fujian (a) and Shanxi (b) provinces

volume is large, it means that large enterprises are more involved.

Figure 6 shows the statistics of COD and $\mathrm{NH}_{3}-\mathrm{N}$ transactions between the 10 industries in Fujian Province, Fig. 7 in Shanxi. In Figs. 6 and 7, the first row in each unit represents the tradable level, the second row represents the participation rate, and the third row represents the trading volume. Tables 6 and 7 summarize the participation and trading volume of Fujian and Shanxi Province's $\mathrm{COD}$ and $\mathrm{NH}_{3}-\mathrm{N}$ trading belonging to each tradable level.

From Figs. 6, 7 and Tables 6, 7, it can be known that the proportion of transactions volume subordinated to level IV and level V is relatively small, which means that the two parties involved in the trading are actually not very close in terms of wastewater pollutant composition. When there is a large difference in the composition of pollutants, it will cause an increase in emissions of other non-in-trade pollutants during the WET process, which is unfavorable to environmental protection. The cause of this problem is, first of all, the imperfection of the WET system. Rules and regulations do not necessarily precede the practice, but must be constantly improved [44]. Policies can neither completely hand over a system to the market economy, nor rely solely on the government to force it. Existing WETs to a large extent develop randomly. This is why we are trying to find suitable rules and restrictions in this paper. The rule design in the article only provides a policy orientation, the real WET still 


\begin{tabular}{|c|c|c|c|c|c|c|c|c|c|c|}
\hline $\mathbf{a}$ & FP & $\mathrm{T}$ & PP & $\mathrm{PCN}$ & CP & PI & MP & GPM & TE & $\mathrm{EE}$ \\
\hline FP & $\mathrm{V}$ & II & II & II & II & II & I & II & II & II \\
\hline $\mathrm{T}$ & II & $\mathrm{V}$ & $\mathrm{V}$ & II & II & II & II & II & III & III \\
\hline \multirow[t]{3}{*}{ PP } & II & $\mathrm{V}$ & $\mathrm{V}$ & & II & II & II & II & III & III \\
\hline & $41.5 \%$ & $4.2 \%$ & $7.4 \%$ & II & $4.8 \%$ & $5.5 \%$ & $19.9 \%$ & $3.2 \%$ & $4.2 \%$ & $9.3 \%$ \\
\hline & $31 \%$ & $2.6 \%$ & $17.1 \%$ & & $22.4 \%$ & $6.1 \%$ & $9.6 \%$ & $1 \%$ & $3.4 \%$ & $6.9 \%$ \\
\hline $\mathrm{PCN}$ & II & II & II & $\mathrm{V}$ & IV & III & II & II & II & III \\
\hline CP & II & II & II & IV & V & IV & II & II & II & III \\
\hline PI & II & II & II & III & IV & V & II & II & II & II \\
\hline MP & I & II & II & II & II & II & V & III & III & II \\
\hline GPM & II & II & II & II & II & II & III & V & $\mathrm{V}$ & IV \\
\hline $\mathrm{TE}$ & II & III & III & II & II & II & III & $\mathrm{V}$ & $\mathrm{V}$ & IV \\
\hline $\mathrm{EE}$ & II & III & III & III & III & II & II & IV & IV & $\mathrm{V}$ \\
\hline b & FP & $\mathrm{T}$ & PP & PCN & $\mathrm{CP}$ & PI & MP & GPM & $\mathrm{TE}$ & $\mathrm{EE}$ \\
\hline FP & $\mathrm{V}$ & II & II & II & II & II & I & II & II & II \\
\hline $\mathrm{T}$ & II & V & V & II & II & II & II & II & III & III \\
\hline \multirow[t]{3}{*}{ PP } & II & V & V & & II & II & II & II & III & III \\
\hline & $36.8 \%$ & $2.3 \%$ & $5.7 \%$ & II & $3 \%$ & $4 \%$ & $13 \%$ & $2 \%$ & $2.7 \%$ & $5.4 \%$ \\
\hline & $48.7 \%$ & $0.9 \%$ & $3.9 \%$ & & $3.2 \%$ & $5.6 \%$ & $11.5 \%$ & $1.5 \%$ & $2.4 \%$ & $3.8 \%$ \\
\hline \multirow[t]{3}{*}{$\mathrm{PCN}$} & II & II & II & & IV & III & II & II & II & III \\
\hline & $12 \%$ & $2 \%$ & $1.3 \%$ & V & $0.7 \%$ & $1.7 \%$ & $3.3 \%$ & $1.3 \%$ & $1 \%$ & $1.7 \%$ \\
\hline & $10.7 \%$ & $1.3 \%$ & $0.2 \%$ & & $0.1 \%$ & $1.6 \%$ & $1.1 \%$ & $0.5 \%$ & $0.3 \%$ & $2.8 \%$ \\
\hline CP & II & II & II & IV & V & IV & II & II & II & III \\
\hline PI & II & II & II & III & IV & V & II & II & II & II \\
\hline MP & I & II & II & II & II & II & V & III & III & II \\
\hline GPM & II & II & II & II & II & II & III & $\mathrm{V}$ & $\mathrm{V}$ & IV \\
\hline $\mathrm{TE}$ & II & III & III & II & II & II & III & $\mathrm{V}$ & $\mathrm{V}$ & IV \\
\hline $\mathrm{EE}$ & II & III & III & III & III & II & II & IV & IV & V \\
\hline
\end{tabular}

Fig. 6 COD and NH3-N trading data in Fujian

requires government regulation and enterprises emission reduction cooperation actively.

Despite the disorder of pilot WET program, promotion on active emission reduction and clean manufacturing of policy is obvious. Some heavy pollution industries no longer passively respond to environmental protection pressure. Among the supply side in Fujian Province, there are two noticeable enterprises-Qingshan Paper Industry Co., Ltd and Sangang Steel Industry Co., Ltd, that supply almost all the COD and $\mathrm{NH}_{3}-\mathrm{N}$ emission right. Investigation of environment disclosure information and corporate annual report reveal that these two national key monitoring enterprises not only strictly discharge wastewater below industrial standard, but proactively improve production process and adopt cleaner production technology according to clean manufacturing index. For example, the total permit of COD in Qingshan is $1745.5 \mathrm{t}$, and it has been declining from $1555.48 \mathrm{t}$ in the year 2015 to $503.81 \mathrm{t}$ in 2019. Surplus emission quota is thus generated. It is the decision of enterprise to reduce emissions driven by economic benefits. Although our article discusses the missing

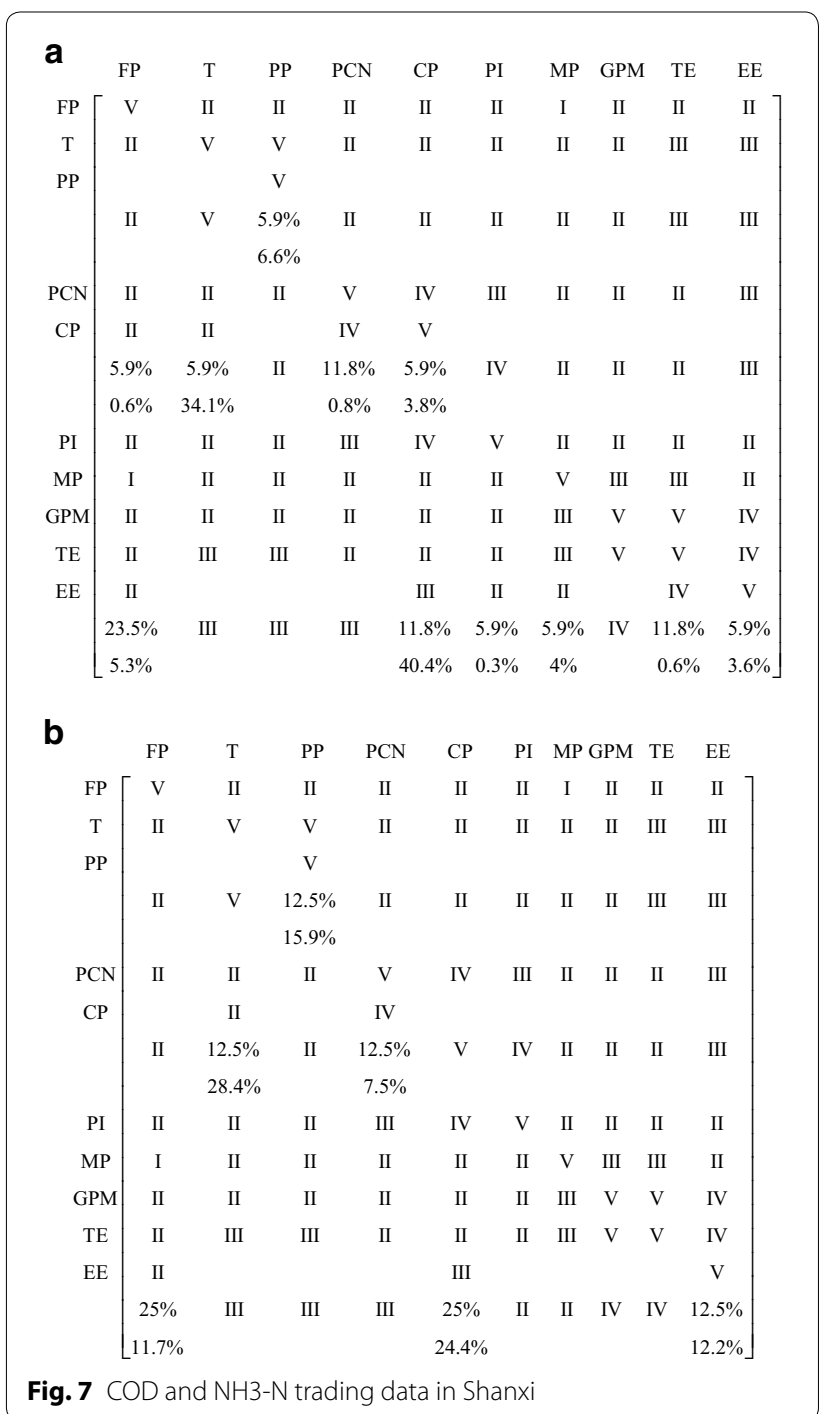

Table 6 Participation and transaction volume of Fujian Province's WET

\begin{tabular}{lllllll}
\hline & & I & II & III & IV & V \\
\hline COD & $P$ & $0 \%$ & $74.7 \%$ & $13.6 \%$ & $0 \%$ & $11.7 \%$ \\
& $V$ & $0 \%$ & $70 \%$ & $10.3 \%$ & $0 \%$ & $19.7 \%$ \\
$\mathrm{NH}_{3}-\mathrm{N}$ & $\mathrm{P}$ & $0 \%$ & $79.8 \%$ & $11.5 \%$ & $0.7 \%$ & $8 \%$ \\
& $\mathrm{~V}$ & $0 \%$ & $84.5 \%$ & $10.6 \%$ & $0.1 \%$ & $4.8 \%$ \\
\hline
\end{tabular}

part of this policy, the positive role of this policy is also worth studying. Taking advantage of economic incentive to stimulate transformation of high emission and heavy pollution industries to update technology and reduce emission, original intention of the environmental economic policy thus could be realized. 
Table 7 Participation and transaction volume of Shanxi Province's WET

\begin{tabular}{lllllcl}
\hline & & I & II & III & IV & V \\
\hline COD & $\mathrm{P}$ & $0 \%$ & $47.1 \%$ & $11.8 \%$ & $23.6 \%$ & $17.7 \%$ \\
& $\mathrm{~V}$ & $0 \%$ & $44.2 \%$ & $40.4 \%$ & $1.4 \%$ & $14 \%$ \\
$\mathrm{NH}_{3}-\mathrm{N}$ & $\mathrm{P}$ & $0 \%$ & $37.5 \%$ & $25 \%$ & 12.5 & $25 \%$ \\
& $\mathrm{~V}$ & $0 \%$ & $40.1 \%$ & $24.4 \%$ & $7.5 \%$ & $28.1 \%$ \\
\hline
\end{tabular}

\section{Conclusion}

Detailed rules are needed to implement the WET policy. This article designs rules and restrictions for WET across different industries and meanwhile discusses in detail the differences in wastewater nature and abatement costs of the ten industries. Then, a similarity principle is proposed to analyze the similarity of wastewater compositions in different industries through algorithms. The result shows that of all industrial wastewater, the most suitable for trading can be divided into three groups: non-degradable biochemical wastewater, mechanical wastewater, and chemical and pharmaceutical wastewater. Other types of industrial wastewater are not suitable for trading with each other due to their different properties. The theoretical framework and calculation methods are optimized, yet the shortcoming is that the industrial wastewater discharge data in the article are based on limited statistical data. If a large amount of corporate environmental monitoring data are available, the accuracy of the results will be improved. Analysis of the pilot WET situation demonstrates that existing WETs to a large extent are randomly inconsistent with the rules. However, there are also enterprises that actively carry out technological innovation and achieve emission reductions under economic incentive. The rule design in the article only provides a policy orientation; the real water pollution trading still requires government regulation and enterprises emission reduction cooperation actively.

\begin{abstract}
Abbreviations
COD: Chemical oxygen demand; $\mathrm{NH}_{3}-\mathrm{N}$ : Ammonia nitrogen; GDP: Gross domestic product; ET: Emissions trading; WET: Wastewater emissions trading; NPSI: National Pollution Source Investigation; ICNEA: Industrial Classification for National Economic Activities; PP: Paper products; T: Textile; FP: Food products; PCN: Petroleum, Coking, Nuclear Fuel; CP: Raw Chemical Materials and Chemical Products; PI: Pharmaceutical; MP: Metal products; GPM: General Purpose Machinery; TE: Transport Equipment; EE: Electrical Machinery And Equipment; VP: Volatile Phenol; CN-: Cyanide.
\end{abstract}

\section{Acknowledgements}

Not applicable.

\section{Authors' contributions}

$\mathrm{HZY}$ contributed to the classification of wastewater indicators and corresponded to the whole paper; LYC designed the theoretical framework, wrote the manuscript and conducted the data analysis; HYZ helped to collect the wastewater emissions trading record data. All authors read and approved the final manuscript.

\section{Funding}

No funding

Availability of data and materials

The datasets obtained and analyzed during the current study are available in the "China Environmental Protection and Economic and Social Development Statistics Database", http://data.cnki.net/Trade/Home/Index/Z008?uid=WEEvR EcwSIJHSIdRa1FhdXNXaEhoRFQwald2Mi9sWmFhczEvb2FXKOVrbz0 $=\$ 9 \mathrm{~A} 4 \mathrm{hF}$ _YAuvQ5obgVAqNKPCYcEjKensW4IQMovwHtwkF4VYPoHbKxJw.

Ethics approval and consent to participate

Not applicable.

\section{Consent for publication}

Not applicable.

\section{Competing interests}

The authors declare that they have no competing interests.

\section{Author details}

${ }^{1}$ College of Environmental Science and Engineering, Tongji University, No. 1239, Siping Road, Shanghai 200092, China. ${ }^{2}$ State Key Laboratory of Pollution Control and Resource Reuse, Tongji University, Shanghai 200092, China.

Received: 28 December 2019 Accepted: 23 March 2020

Published online: 22 April 2020

\section{References}

1. National Bureau of Statistics (NBS), Ministry of Ecology and Environment (MEE) (2019) China statistical yearbook on environment 2019. China Statistics Press, Beijing

2. National Bureau of Statistics (NBS) (2017) China industry statistical yearbook 2017. China Statistics Press, Beijing

3. Zhang B, Zhang H, Liu BB et al (2013) Environ Sci Technol 47(13):7077-7084

4. Li XL, Yang XJ, Wei Q, Zhang B (2019) Authoritarian environmentalism and environmental policy implementation in China. Resour Conserv Recycl 145:86-93

5. Dales JH (1968) Pollution, property and prices: an essay in policy-making and economics. University of Toronto, Toronto

6. Montgomery WD (1972) Markets in licenses and efficient pollution control programs. J Econ Theory 5(3):395-418

7. Lyon TP (2012) Environmental governance: an economic perspective. In: Delmas MA, Young OR (eds) Governance the environment: new perspectives. Cambridge University Press, Cambridge

8. Yenipazarli A (2019) Incentives for environmental research and development: consumer preferences, competitive pressure and emissions taxation. Eur J Oper Res 276:757-769

9. Krupnick AJ (1986) Costs of alternative policies for the control of nitrogen dioxide in Baltimore. J Environ Econ Manage 13:189-197

10. Stranlund JK, Chavez CA, Field BC (2002) Enforcing emissions trading programs. Policy Stud J 30(3):343-361

11. Felli R (2015) Environment, not planning: the neoliberal depoliticisation of environmental policy by means of emissions trading. Environ Polit 24(5):641-660

12. Feng $Y$ (2016) Environmental management and pollution cost management. Tsinghua University Press, Beijing

13. Speed R (2009) A comparison of water rights systems in China and Australia. Water Resour Dev 25(2):389-405

14. Borghesi S (2013) Water tradable permits: a review of theoretical and case studies. J Environ Plann Manage 57(9):1305-1332

15. Cai CZ, Dong ZF, Li XL et al (2019) 40 years of environmental policy reform in China. China Environmental Publishing Group, Beijing

16. Chang YC, Wang N (2010) Environmental regulations and emissions trading in China. Energy Policy 38:3356-3364 
17. Shen MH, Qian SM, Feng YQ et al (2009) The mechanism of emission trading. China Environmental Science Press, Beijing

18. Zhang B, Fei H, He P et al (2016) The indecisive role of the market in China's $\mathrm{SO}_{2}$ and COD emissions trading. Environ Polit 25(5):875-898

19. 13th Five Year Ecological Planning (2016) The State Council

20. Snell C, Haq G (2014) The short guide to environmental policy. The Policy Press, Bristol

21. Cao H, Ikeda S (2005) Inter-zonal tradable discharge permit system to control water pollution in Tianjin, China. Environ Sci Technol 39(13):4692-4699

22. Luo QL, Luo LY, Zhou QF et al (2019) Does China's Yangtze River Economic Belt policy impact on local ecosystem services? Sci Total Environ 676:231-241

23. The overall plan of the Yangtze River Delta ecological green integration development demonstration zone (2019) The State Council

24. Wang LP (2018) Low carbon and emission trading: the case study of Henan. China Economic Publishing House, Beijing

25. Wan W, Zhang SQ (2012) Can emission trading policy help restructuring industry? A case study in Shenzhen of China. Acta Scientiarum Naturalium Universitatis Pekinensis 48(3):491-499

26. Yang SY (2004) Background and present situation on tradable construct of emission permits. Environ Protect 11:48-52

27. Hung MF, Shaw D (2005) A trading-ratio system for trading water pollution discharge permits. J Environ Econ Manage 49(1):83-102

28. Emission trading needs top-level design-China $\mathrm{H}_{2} \mathrm{O}$ website. http:// www.h2o-china.com/news/259460.html. Assessed 25 Dec 2019. (in Chinese)

29. Zhejiang emission trading center. http://www.zjpwq.net/cms/. Assessed 25 Dec 2019. (in Chinese)

30. Notice on paid use of pollution discharge rights and transaction charges (2017) Nanjing Ecological Environment Bureau

31. Implementation Plan of Cleaner Production Technology in Key Industries of Water Pollution Prevention (2016) Ministry of Industry and Information Technology, Ministry of Ecology and Environment

32. National Engineering and Technology Research Center for urban environmental pollution control (2010) Technical manual of three wastes treatment engineering. Chemical Industry Press, Beijing
33. Zou JQ (2003) Industrial wastewater treatment technology. Chemical Industry Press, Beijing

34. Yang M, Zhang M, Gao YX (2019) Principle and application of industrial wastewater treatment and resource technology. Chemical Industry Press, Beijing

35. Yang ZL (2001) Research on the methodology and technique of water pollution emissions trading. PhD thesis. Hohai university, Nanjing, China

36. US EPA (2007) Water quality trading toolkit for permit writers

37. Kou G, Lin CS (2014) A cosine maximization method for the priority vector derivation in AHP. Eur J Oper Res 235(1):225-232

38. Qiu WH (2002) Management decision and applied entropy. China Machine Press, Beijing, pp 193-196

39. Zou ZH, Yun Y, Sun JN (2006) Entropy method for determination of weight of evaluating indicators in fuzzy synthetic evaluation for water quality assessment. J Environ Sci 18(5):1020-1023

40. Narsimha A, Qian H, Li PY (2019) Entropy water quality index and probabilistic health risk assessment from geochemistry of groundwaters in hard rock terrain of Nanganur County. Geochemistry, South India. https:// doi.org/10.1016/j.chemer.2019.125544s

41. Chang NB, Chen HW, Ning SK (2001) Identification of river water quality using the Fuzzy Synthetic Evaluation approach. J Environ Manage 63(3):293-305

42. Icaga Y (2007) Fuzzy evaluation of water quality classification. Ecol Ind 7(3):710-718

43. Chinese Academy of Environmental Planning, Ministry of Ecology and Environment (2018) Environmental Economic Policy Annual Report 2018

44. Shen MH, Zhou SX, Xie HM et al (2014) The studies of supervision mechanism for pollution rights. China Environmental Science Press, Beijing

\section{Publisher's Note}

Springer Nature remains neutral with regard to jurisdictional claims in published maps and institutional affiliations.

\section{Submit your manuscript to a SpringerOpen ${ }^{\circ}$ journal and benefit from:}

- Convenient online submission

- Rigorous peer review

- Open access: articles freely available online

- High visibility within the field

- Retaining the copyright to your article

Submit your next manuscript at $\boldsymbol{\nabla}$ springeropen.com 